\title{
Effectiveness of Hot Application with Breast Massage on Breast Engorgement Among the Postnatal Mothers
}

\author{
Ms. Sangeeta Thakur ${ }^{1}$, Mrs. Gomathi B ${ }^{2}$, Ms. Kanchan Bala ${ }^{2}$ \\ ${ }^{1}$ M.Sc. Nursing, ${ }^{2}$ Assistant professor \\ Himalayan College of Nursing, Swami Rama Himalayan University, \\ Dehradun, Uttarakhand, India
}

\begin{abstract}
Breast engorgement is one of the most common breast implications occur on 2 nd and 3 rd postnatal days. A quasi experimental time series design study was conducted to assess the Effectiveness of hot application with breast massage on breast engorgement among the postnatal mothers. The study was conducted on 60 postnatal mothers who had breast engorgement which were randomly divided into two groups (30 in experimental group and 30 in control group) and samples were selected through purposive sampling technique. The study was explained to participants and consent was taken. The data were collected by six point breast engorgement scale, numerical pain scale and through oppinionaire. For the experimental group sponge cloth over the breast for a total duration of 20 minutes for 3 times in day continues for 2 days. Posttest for breast engorgement and pain was assessed in study and control group at the same interval. Homogeneity was maintained for demographic variables in both groups. The result showed that there was significant difference between both the groups showed a significant reduction in breast engorgement at $p<0.05$ This study found that hot application with breast massage is effective in reducing the breast engorgement among postnatal mothers.
\end{abstract}

Keyword: Effectiveness, hot application, breast massage, breast engorgement, postnatal mother.

\section{INTRODUCTION}

Breast feeding is a natural human activity and best method for feeding an infant. World health organization suggest that exclusive breast feeding for at least six months of life and continue supplement breast feeding for at least one year. Mother ship is a

joyful event, when a woman gives birth to a baby, despite of tremendous pain and discomfort. ${ }^{1}$

Various physiological changes occurs in the body of women during pregnancy. Breast engorgement is a painful condition which is mostly occur on $2^{\text {nd }}$ and $3^{\text {rd }}$ postpartum period which makes the breasts feel swollen, sore, tingly, and unusually sensitive to touch. ${ }^{2}$

Breast engorgement prevents the baby from latching preventing effective breast milk flow. This leads to severe breast engorgement, which can cause great discomfort and pain. Insufficient breast milk intake will subsequently occur and hinder normal infant growth and health of mother. ${ }^{3}$

Global rate of exclusive breastfeeding according to WHO (2013) is 37\%. Indian statistics suggests $96 \%$ of the children are breastfed, of that only $29 \%$ of the urban population and $21 \%$ of the rural population are breastfed within an hour immediately after birth. Breastfeeding problems such as breast engorgement, flat or inverted nipple or mastitis were detected in $4.9 \%$ of the women in India. ${ }^{4}$

\section{PROBLEM STATEMENT}

"A study on effectiveness of hot application with breast massage on breast engorgement among the postnatal mothers admitted in postnatal ward of selected hospital, Dehradun, Uttrakhand."

\section{OBJECTIVES:}

1. To assess the effect of hot application with breast massage on breast engorgement among the postnatal mothers with breast engorgement. 
2. To find association between the level of breast engorgement with their selected demographic variables of postnatal mothers

3. To assess the opinion of postnatal mothers about hot application with breast massage.

\section{HYPOTHESES}

All hypotheses were tested at $p<0.05$ level of significance

$\mathrm{H}_{1}$ : There would be significant reduction in the mean breast engorgement score of postnatal mothers of experimental group than in control group.

$\mathrm{H}_{2}$ : There would be significant association between the breast engorgement score and the selected demographic variables of postnatal mothers.

\section{METHODOLOGY}

The research design used in this study was quasi experimental with time series design. The study was conducted at Himalayan Hospital, Dehradun, Uttarakhand.60 postnatal mothers were randomly assigned into 30 in experimental and 30 in control group through purposive sampling technique. The data were collected by demographic variables, six point breast engorgement scale, numerical pain scale and oppinionaire the study was explained to participants and written consent was taken. The data were collected with the help of various tools consisting of
Section A. Demographic variables: consists of Age, Parity, Type of family, Occupation, Type of delivery, Educational status, No. of postpartum days, Initiation of breast feeding, Maternal position for breast feeding, Frequency of breast feeding

Section B. Breast engorgement scale: It was developed by Hill\&Humenick. It was used to assess the: degree of breast engorgement which given the scoring ranges from 1 to 6 .

Section C. Opionionnaire: To assess the opinion of postnatal mother regarding hot application with breast massage.

\section{Presentation of the data}

The data was entered in a master sheet, for tabulation and statistical processing. In order to find the relationship, the data was tabulated, analyzed and the interpreted using descriptive and inferential statistical methods. The data was analyzed and the interpretation were drawn

\section{SECTION-A:}

This section deals with the distribution of the study subjects based on their demographic variables such as Parity, Type of family, Occupation ,Type of delivery, Educational status, Initiation of breast feeding ,Maternal position for feeding and Frequency of feeding.

Table No. 1: Frequency and percentage distribution of demographic variables of postnatal mothers

\begin{tabular}{|c|c|c|c|c|c|}
\hline \multirow{2}{*}{$\begin{array}{l}\text { Sr. } \\
\text { no. }\end{array}$} & \multirow[b]{2}{*}{ Demographic variables } & \multirow{2}{*}{$\begin{array}{c}\text { Experimental } \\
\text { Group } \mathbf{n = 3 0}\end{array}$} & \multirow{2}{*}{$\begin{array}{l}\text { Control group } \\
\qquad \mathrm{n}=\mathbf{3 0}\end{array}$} & \multicolumn{2}{|c|}{ Homogeneity } \\
\hline & & & & $\chi^{2}$ & $\begin{array}{c}\text { p- } \\
\text { value }\end{array}$ \\
\hline 1. & $\begin{array}{l}\text { Age } \\
\begin{array}{l}\text { a. } 19-27 \\
\text { b. } 28-36\end{array}\end{array}$ & $\begin{array}{l}17(56.6 \%) \\
13(43.3 \%) \\
\end{array}$ & $\begin{array}{c}20(66.6) \\
10(33.3 \%)\end{array}$ & $0.716 "$ & 0.470 \\
\hline 2. & $\begin{array}{l}\text { Parity } \\
\text { a. Primiparous } \\
\text { b. Multiparous }\end{array}$ & $\begin{array}{l}17(56.7 \%) \\
12(43.3 \%)\end{array}$ & $\begin{array}{l}14(46.7 \%) \\
16(53.3 \%) \\
\end{array}$ & $0.475^{\prime \prime}$ & 0.713 \\
\hline 3. & $\begin{array}{c}\text { Type of family } \\
\text { a. Nuclear } \\
\text { b. Joint }\end{array}$ & $\begin{array}{c}8(26.7 \%) \\
22(73.3 \%)\end{array}$ & $\begin{array}{c}7(23.3 \%) \\
23(76.7 \%)\end{array}$ & & 0.345 \\
\hline 4. & $\begin{array}{l}\text { Occupation } \\
\text { a. House wives } \\
\text { b. Working }\end{array}$ & $\begin{array}{c}26(86.7 \%) \\
4(13.3 \%) \\
\end{array}$ & $\begin{array}{c}26(86.7 \%) \\
4(13.3 \%) \\
\end{array}$ & & 0.169 \\
\hline 5. & $\begin{array}{c}\text { Type of delivery } \\
\text { a. vaginal } \\
\text { b. CS }\end{array}$ & $\begin{array}{c}10(33.3 \%) \\
20(66.7 \%)\end{array}$ & $\begin{array}{l}13(43.3 \%) \\
17(56.7 \%)\end{array}$ & & 1.000 \\
\hline
\end{tabular}


International Journal of Trend in Scientific Research and Development (IJTSRD) ISSN: 2456-6470

\begin{tabular}{|c|c|c|c|c|c|}
\hline 6. & $\begin{array}{l}\text { Educational status } \\
\text { a. No formal education } \\
\text { b. Primary } \\
\text { c. Secondary } \\
\text { d. Higher secondary } \\
\text { e. Graduate and above }\end{array}$ & $\begin{array}{l}1(3.3 \%) \\
2(6.7 \%) \\
6(20.0 \%) \\
5(16.7 \%) \\
16(53.3) \\
\end{array}$ & $\begin{array}{c}2(6.7 \%) \\
3(10.0 \%) \\
3(10.0 \%) \\
5(16.7 \%) \\
17(56.7 \%) \\
\end{array}$ & $17.423^{\approx}$ & 0.313 \\
\hline 7 & $\begin{array}{l}\text { No. of post-partum days } \\
\begin{array}{l}\text { a. } \\
\text { b. }\end{array} \text { 5-7 days days }\end{array}$ & $\begin{array}{c}29(96.6 \%) \\
1(3.33 \%)\end{array}$ & $\begin{array}{l}27(90 \%) \\
3(10.0 \%)\end{array}$ & $0.385^{\approx}$ & 0.639 \\
\hline 8. & $\begin{array}{c}\text { Initiation of breast feeding } \\
\text { a. Within } 1 / 2 \text { hour } \\
\text { b. } 1 / 2 \text { hour to } 6 \text { hour } \\
\text { c. } 6 \text { hrs to } 12 \mathrm{hrs} \text {. } \\
\text { d. More than } 12 \mathrm{hrs} \text {. }\end{array}$ & $\begin{array}{l}3(10.0 \%) \\
5(16.7 \%) \\
10(33.3 \%) \\
12(40.0 \%) \\
\end{array}$ & $\begin{array}{l}2(6.7 \%) \\
8(26.7 \%) \\
14(46.7 \%) \\
6(20.0 \%) \\
\end{array}$ & $13.140^{\approx}$ & 0.067 \\
\hline 9. & $\begin{array}{c}\text { Maternal position for feedin } \\
\text { a. Sitting } \\
\text { b. Side lying }\end{array}$ & $\begin{array}{l}17(56.7 \%) \\
13(43.33 \%) \\
\end{array}$ & $\begin{array}{l}17(56.7 \%) \\
13(43.3 \%)\end{array}$ & 2.222" & 0.264 \\
\hline 10 & $\begin{array}{l}\text { Frequency of feeding (in hours } \\
\text { a. every1hour } \\
\text { b. every } 2 \text { hour } \\
\text { c. every3 hour } \\
\text { d. Demand feeding }\end{array}$ & $\begin{array}{l}8(26.7 \%) \\
9(30.0 \%) \\
3(10.0 \%) \\
10(33.3 \%)\end{array}$ & $\begin{array}{c}3(10 \%) \\
10(33.3 \%) \\
2(6.7 \%) \\
15(50.0 \%)\end{array}$ & $9.048^{\approx}$ & 0.370 \\
\hline
\end{tabular}

df1=3.84 at $p<0.05$ level of significance

Chi- square test (") Fisher's exact test $\left({ }^{\approx}\right)$ Yates 's correction test $(y)$ independent $t$ test

Table no 1: Shown that more than half of the mothers in both group were in the age group between 1927years. In experimental group more than half of the mothers were Primi parous i.e. $56.7 \%$ where as in control group half of the mothers were multiparous i.e.53.3\%. Majority of mothers were from joint families i.e. $73.3 \%$ from experimental group and $76.7 \%$ from the control group. In view of occupational status most of the mothers were housewife $(86.7 \%)$ from both groups. In both groups, majority of the postnatal mothers undergone through LSCS in both groups. In type of education more than half of the mothers were found graduated and above $53.3 \%$ in experimental group and $56.7 \%$ in the control group. In experimental group maximum number of mothers initiates breast feeding in more than $12 \mathrm{hrs}$. i.e. $(40.0 \%)$. Same as in the control group $46.4 \%$ of the mother initiate breast feeding between 6hrs to 12 hrs. . In both groups the preferred maternal position for breast feeding were sitting position i.e. $56.7 \%$ in each group. In both group, maximum number of the postnatal mothers fed their baby on demand i.e. $33.3 \%$ in experimental group and $50 \%$ in the control group. it can also interpreted that the study participants in experimental and control group were equally distributed in terms of parity, type of family, occupation, type of delivery ,education , initiation of breast feeding., maternal position, frequency of feeding. 
Figure no 1: Comparison of level of breast engorgement scores between and with experimental and control group.

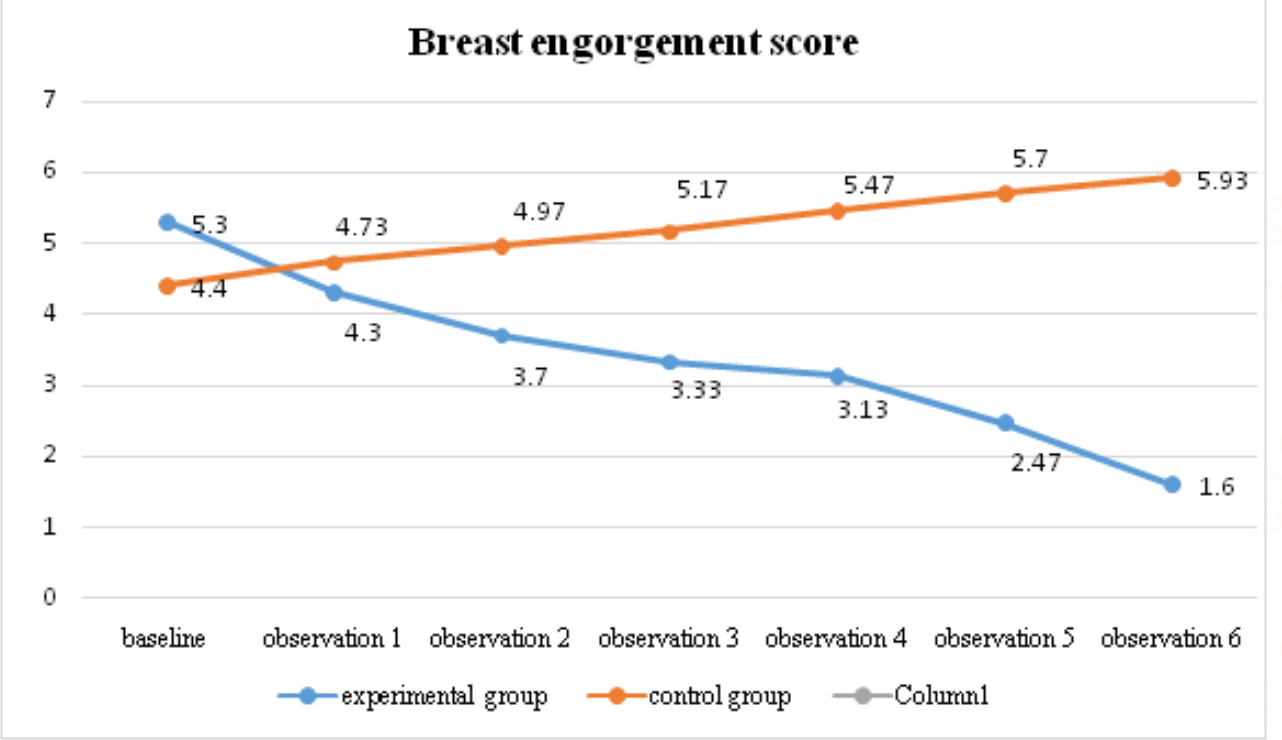

Figure no 1: showed comparison of level of breast engorgement scores between and within experimental and control group it depicts that at baseline the mean breast engorgement score and SD was5.30 \pm 0.702 in experimental group whereas $4.40 \pm 0.770$ in control group. In the observation 6 mean breast engorgement score and SD was $1.60 \pm 0.563$ in experimental group where as $5.93 \pm 0.254$ in control group. Hence, the null hypothesis was rejected and the research hypothesis was accepted. Thus it can be interpreted that the hot application with breast massage is effective in reducing breast engorgement in experimental group than in control group as compared to the control group.

Table no 2: Association of breast engorgement score with selected demographic variables of postnatal mothers with breast engorgement.

\begin{tabular}{|c|c|c|c|c|c|c|}
\hline \multirow{2}{*}{ S. No. } & \multirow{2}{*}{ Demographic variables } & \multicolumn{2}{|c|}{ Breast engorgement score } & \multirow{2}{*}{ Chi-sq. } & Df & p- value \\
\cline { 3 - 5 } \multirow{2}{*}{1} & Type of family & $3-4$ & $5-6$ & & & \\
& a. Nuclear & $10(16.6 \%)$ & $5(8.33 \%)$ & & & \\
& b. Joint & $15(25 \%)$ & $30(50 \%)$ & $5.143 "$ & 1 & 0.035 \\
\hline
\end{tabular}

Table no 2: showed that there was significant it can be interpreted that demographic variables did association found between level of breast not have any influence on breast score of postnatal engorgement score with type of family (5.143) Hence mothers except type of family.

Table no 3: Frequency and percentage distribution of opinionnaire of postnatal mothers regarding hot application with breast massage.

\begin{tabular}{|r|c|c|c|c|c|}
\multicolumn{2}{|c}{ n=30 } \\
\hline \multirow{2}{*}{ S. No. } & Opinions & Strongly Agree & \multicolumn{2}{c|}{ Agree } \\
\cline { 3 - 6 } & & f & $\%$ & f & $\%$ \\
\hline 1. & I felt safe when receiving the intervention. & 28 & 93.3 & 2 & 6.66 \\
\hline 2. & I felt relaxed when receiving intervention. & 24 & 80 & 6 & 20 \\
\hline 3. & I felt relief from breast engorgement after receiving intervention & 25 & 83.3 & 5 & 16.6 \\
\hline 4. & I fed comfortably after receiving the intervention & 25 & 83.3 & 5 & 16.6 \\
\hline 5. & I can share this experience with others. & 30 & 100 & 0 & 0 \\
\hline 6. & I can recommended this method to others. & 30 & 100 & 0 & 0 \\
\hline
\end{tabular}


Table no 3: depicts the frequency and percentage distribution of opinionnaire of mother regarding hot application with breast massage. The result showed that most of the mother $93.3 \%$ were strongly agree whereas $6.66 \%$ of the mothers were agree that they felt safe during the time of intervention. Most of the mothers $80 \%$ were strongly agree whereas $20 \%$ were agree that felt relaxed when receiving the intervention . Most of the mothers $83.3 \%$ were strongly agree whereas $16.6 \%$ were agree that they felt comfortable and relief from breast engorgement after receiving the intervention. All the mothers $(100 \%)$ were strongly agree that they can share and recommend this intervention to others.

\section{DISCUSSION}

The present study was aimed to assess the effectiveness of hot application with breast massage on breast engorgement among postnatal mothers. Findings of present study have been discussed with the references of the objectives and statistical analysis and findings of the other researchers done on same field. Total 60 subjects were selected through purposive sampling technique. Data was collected by using demographic variable, breast engorgement scale and numerical pain scale

The present study revealed that there was significant decrease in breast engorgement score from baseline $(5.30 \pm 0.707)$ to observation $\mathrm{O}_{6}(1.60 \pm .563)$ in experimental group after intervention. There was significant increase in the mean breast engorgement score from baseline $(4.40 \pm .770)$ to observation 06 $(5.93 \pm .254)$ in control group Hence the null hypothesis rejected and the research hypothesis is accepted. This can interpreted that after giving the hot application with breast massage in experimental group there was subsequent decrease in the mean engorgement score,

The study finding was congruent with the study conducted by Disha, Rana A, Amarjeet S, Vanita S (2015) showed that level of breast engorgement decreases after giving the intervention in experimental group than in control group

\section{Conclusion:}

The present study assessed the effectiveness of hot application with breast massage on breast engorgement among postnatal mothers. The study findings revealed that there was a significant difference in the level of breast engorgement among postnatal mothers and the participants were comfortable and cooperative throughout the study. From this it is concluded that hot application with breast massage can be used as a cost effective nursing intervention in reducing the breast engorgement and pain among postnatal mothers

\section{REFERENCES}

1. Manna M, Podder L and Devi S, A study to compare the effectiveness between hot fomentation and cold compression as the treatment of breast engorgement and associate the findings with demographic variables. International Journal of Nursing Research and Practice 2016 (cited on dec 2017) ;3 ( 1): (2016) http://www.uphtr.com/issue_files/Vol\%203,\%20N o\%202\%20\%204\%20Ms\%20Moumita.pdf

2. Bhas D. [INTERNET] Breastfeeding is the key to infant and child survival. December 2009. [Cited dec $13 \quad 2017$ ] Available at: http://infochangeindia.org/publichealth/features/breastf eeding-is-the-key-to-infant-andchild-survival.html.

3. John 1, cordeiro M P and Gopinath R A study to assess the knowledge regarding regarding breast problems among antenatal mothers in selected hospital mangluru with a view to develop an information booklet. International journal of recent scientific research 2015 ( cited on dec 2017); 6(9): pp(6228-6231) available online at http://www.recent scientific.com

4. Resmy V, S. J. Nalini and G. Sumathi V et al. (2014) a study on effect of lukewarm water compress on prevention of nipple pain and breast engorgement among primiparous at a selected hospital in chennai journal of science 2014(cited on jan 2018); 4(10): pp 620-624 available at https://www.scribd.com/document/339560780/Ma ternity-1

5. Anandhi R, Vahita and Sasirekha R, effect of lukewarm water compress on prevention of nipple pain and breast engorgement among postnatal mothers whose babies admitted in nursery at WCH, JIPMER , International Journal of Current Medical and Pharmaceutical Research. 2017 (cited on jan 2018); 3(7):pp2002- 2006 Available at http://journalcmpr.com/sites/default/files/issuefiles/0781-A-2017.pdf 